\title{
Priority Paper
}

\section{An assessment of ecological conditions and threats at the Ethiopian wintering site of the last known eastern colony of Critically Endangered Northern Bald Ibis Geronticus eremita}

\author{
G. SERRA, C. BRUSCHINI, L. PESKE, A. KUBSA, M. WONDAFRASH and J. A. LINDSELL
}

\begin{abstract}
Summary
The long-range, migratory eastern relict population of Northern Bald Ibis Geronticus eremita has been steadily declining since the time of discovery in 2002, despite the protection programme in place at the breeding grounds in Syria. Assessing the ecological conditions and threats along the migration route and at the wintering site, both discovered in 2006, has become a priority for this "Critically Endangered" species. Adult ibises spent the winter at the same site on the central Ethiopian highland plateau, from August until mid-February during five consecutive winters (2006-2011). The wintering site was surveyed during four field visits and assessed through a spatial analysis of 1,067 satellite locations. The site is in an agro-pastoral landscape, inhabited by a settled community of people living in relatively poor and isolated conditions. Home range analysis based on kernel distributions showed that the bald ibises used a core range area of $9.1-19.0 \mathrm{~km}^{2}$ (confirmed by direct visual observations in the field) and an extended range area of 61.0-126.1 $\mathrm{km}^{2}$. These figures are c.20 and 6o times smaller, respectively, than those calculated for the breeding site in Syria. Eighty-one percent of the core area in Ethiopia was used in all five years confirming the birds' fidelity to this wintering site. Ibises preferred to forage in wet or dry pastures and in recently cut hayfields, and avoided tall grass, uncut hayfields and cultivation. Despite dependence on human-created habitats, human disturbance observed in the field was minimal. The main short-term threat for the ibises was judged to be the potential raising of attention on the part of the local community specifically towards these few individual ibises. In the medium term, the main threat comes from the conversion of pastures into crops and the potential use of fertilisers and pesticides.
\end{abstract}

\section{Introduction}

Persistent population declines in Palearctic breeding birds are disproportionately concentrated in long distance migrants (Sanderson et al. 2006). Many causes for migrant declines have been proposed. One leading hypothesis is that unfavourable conditions at the wintering grounds or along migration routes cause reduced survival (Newton 2004). Palearctic migrants wintering in Africa are one group that may be particularly vulnerable to changes on the wintering grounds given the impacts of climate change at the edges of the Sahara which are critical areas for migrants (Zwarts et al. 2009) and the effects of population growth and economic development on land-cover 
throughout the continent (Tilman et al. 2002, Soderstrom et al. 2003, FAOSTAT database of the UN FAO). Declines in bird species breeding in the UK have been more pronounced for migrants over-wintering within African humid zones (Thaxter et al. 2010). Ascertaining the cause of any population decline is difficult (Sanderson et al. 2006) and the wintering grounds and ecology of most species are very poorly known (Bairlein 2003). Demonstrating the impact of wintering conditions on breeding declines requires explicit connections to be made between wintering and breeding populations (Webster et al. 2002, Thaxter et al. 2010). Long-term ringing datasets have provided connections to some degree (Wernham et al. 2002) though many species remain poorly sampled in the wintering areas. More recently, satellite tracking has allowed direct observation of these connections (Meyburg and Meyburg 2007) which has allowed assessment of specific wintering sites used by specific breeding populations, though the occasions on which this has been done explicitly are rather few (Bobek et al. 2008). However, this kind of detailed diagnosis will be essential if declines in migratory species are to be stemmed. The "Critically Endangered" Northern Bald Ibis Geronticus eremita (BirdLife International 2004) has been considered sedentary on the basis of the majority Moroccan population though the eastern population has long been known to seasonally migrate from their breeding areas. Recent work has demonstrated that they are long distance migrants (Lindsell et al. 2009). In the east their breeding population fell catastrophically during the $20^{\text {th }}$ century, finally being declared extinct in the region in 1989 (Akcakaya 1990). Remarkably, a small relict colony of wild birds was discovered in 2002 still breeding in Syria (Serra et al. 2004), but despite intensive protection it had declined to just one pair in 2011. There is an urgent need to identify what is driving the decline of this particular population to have a chance of saving them from extinction. Breeding productivity between 2002 and 2011 averaged 1.3 fledglings per nesting attempt (Serra et al. 2009a and unpubl. data), which compares favourably with the Moroccan population (Bowden et al. 2008). Deaths of fully-grown and immature birds were concentrated outside the breeding grounds and the mortality rate of immature birds during the 2-4 year period before their return to the natal site (Serra et al. 2009b, Serra et al. in press) seems significantly higher than those recorded in similar species (Bairlein 1981, Schultz et al. 1988, Menu et al. 2005, Pistorius et al. 2006, Gauthier et al. 2010). The ecology of the Northern Bald Ibis at the Syrian breeding site is well known (Serra et al. 2008, 2009b, Lindsell et al. 2011) but no data are available about the species' behavioural ecology, habitat requirements and potential threats on their wintering grounds. In the present study, we sought to determine whether conditions at the wintering site could underlie the failure of this population to improve its status in recent years (Kanyamibwa et al. 1990, Berthold and Terrill 1991, Saino et al. 2004).

\section{Methods}

\section{Study area}

The Northern Bald Ibis wintering range (hereafter IWR) is located north of Addis Ababa, Ethiopia, in a remote part of Oromia Regional State, near the border with Amhara Regional State. The site is on the central Ethiopian highland plateau, and is relatively flat and undulating with an altitude ranging between 2,600 and 3,100 $\mathrm{m}$ asl. The geographical coordinates of the site are not disclosed for conservation reasons. Settled communities live in scattered settlements located on the tops of gently undulating hills. Mainly teff but also wheat, barley and oats are cultivated on slopes around settlements. Hay is grown in wetter areas along watercourses beside pastures that are also found in higher drier areas. The native vegetation cover of the IWR has been almost totally removed - except for some scattered Acacia trees and some scrub on the fringes of settlements left for protection and shade. Introduced Eucalyptus trees grown for shade and wood predominate around settlements. Observations in other parts of the Ethiopian highlands suggest that the proportion of pastures compared with cultivated fields is relatively high in IWR. There are two wet seasons in this part of the Ethiopian highlands with long rains between July and November and short rains between February and April. At other times it is largely dry. The highest daily 
temperature range is experienced during the long dry season (November-February). The climate in November 2006 and 2008 was sunny during daytime but cold at night, with an average temperature of $12.6^{\circ} \mathrm{C}$ ( $\min :-6^{\circ} \mathrm{C}$; $\max : 24^{\circ} \mathrm{C}$ ).

\section{Satellite data collection and analysis}

Ibises were tagged with satellite PTTs at breeding grounds in Syria in 2006 (Lindsell et al. 2009). Three satellite tags operated for two winters and one operated discontinuously for five winters. Satellite tags had VHF transmitters attached that operated during the first winter only. Satelliteacquired locations in five consecutive winters $(2006-2011 ; n=1,067)$ were filtered to retain only LC class O-3 (Argos User's Manual: http://www.cls.fr/manual). We used all LC o-3 locations (diurnal and nocturnal) for estimating the total IWR, but only LC $2-3$ diurnal locations were used for estimating the foraging range because the error associated with less accurate locations is greater than the distances between foraging areas. In order to minimise autocorrelation in the location data we only retained locations that were closer than $3 \mathrm{~km}$ to each other, provided more than three hours had lapsed between them. This was in response to field observations indicating that birds often remained in a single foraging area (c.I-3 km in diameter) for protracted periods of time. In order to deal with the high rates of error in Argos location classes (an estimate of $33.3 \%$ as indicated in the Argos User's Manual) we further filtered the location data to discard isolated locations which implied very rapid long distance movements or repeated crossing back and forth across the range; isolated locations that were considered unlikely based on field observations and observed ibis behaviour; isolated nocturnal locations that were distant from the known (or any potential) roost site. Satellite locations were mapped and analysed using ArcGIS 9.2 software (Ackerman et al. 1989, Rodgers and Carr 1998). We used the fixed-kernel range estimator (Worton 1989, 1995) to estimate the 50\% and 95\% utilisation distribution with Hawth's Analysis Tools extension (www.spatialecology.com/htools/index.php). Satellite telemetry in combination with kernel fitting has been widely employed for the purpose of estimating the spatial range used by wildlife (e.g. Hobbs et al. 2005, Vashon et al. 2008). We selected a smoothing parameter $(\mathrm{H})$ of 1,500 as it minimised the formation of unrealistic isolated clusters at the range edge. Kernel distributions were considered to be the most reliable means of estimating the central area of the IWR (50\% core range) and the closest approximation of the total IWR (95\%, wider or extended range) (Wiktander et al. 2001, Broomhall et al. 2003). The areas concerned (based on $50 \%$ and $95 \%$ volume contours) were compared with those from breeding grounds in Syria by using the same smoothing parameter (least squares cross-validation; Seaman and Powell 1996, Hooge et al. 2004).

\section{Field surveys}

Four surveys were carried out at the IWR in November 2006 (II days), October 2007 (2 days), November 2008 (7 days) and January 2009 (4 days) guided by satellite locations. Besides the three tagged birds there was one untagged adult bird present during 2006-2009 (at least two different individuals during the period) but in 2011 two unidentified subadult birds were also present (Dellelegn 2011). The total number of birds present declined during the study, across subsequent winters, which was attributed to mortality (Table I). Great care was taken to ensure the attention of the local population was not drawn towards the ibises by our activities. The roost site used by the ibises was monitored at roosting time (17h30-18hoo) and during the pre-dawn period (o6hoo-06h15) on at least three different days in 2006. On four different days across three surveys (2006, 2008 and 2009) the birds were observed continuously from their time of departure from their roost until they returned to it after sunset, recording every 10 minutes their behaviour, habitat use and any other significant observation. Due to the VHF transmitters (in 2006 only), their relatively small home range and their repetitive behaviour, the birds' locations could be identified at any time. Foraging habitat use was assessed by recording the proportion of time spent foraging by birds in each habitat, within 1o-minute intervals across the whole day. 


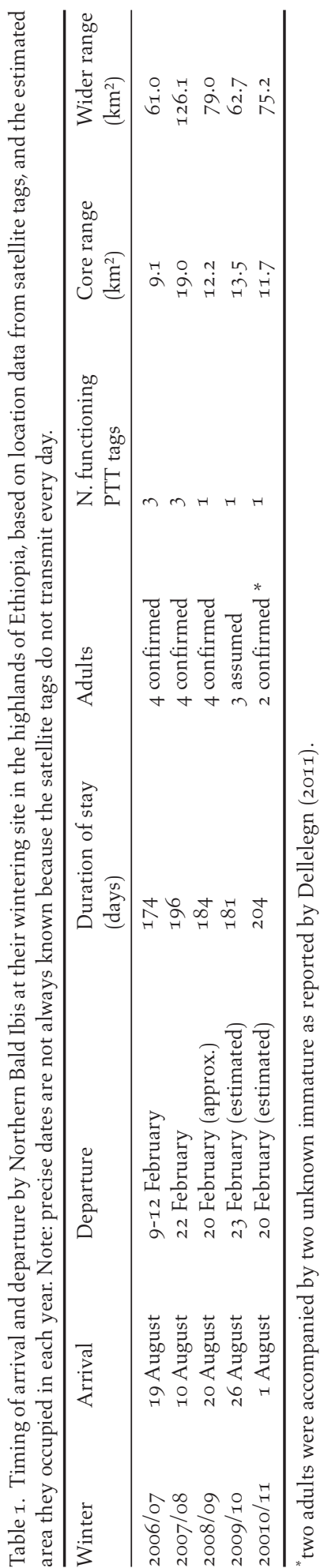


The average use over two days was calculated for November 2006 and for November 2008January 2009, separately. Relative availability of foraging habitats was assessed using a GPS for two foraging areas (November 2006) and for the whole IWR (November 2008 and January 2009). The chi-squared goodness-of-fit test was used to test the null hypothesis that habitat usage by ibises occurred in proportion to availability (alpha level of 0.05). We distinguished foraging areas and foraging sites (sensu Bowden and Smith 1997) such that foraging areas were the overall areas used by the birds either by walking or by short-distance flights $(<200 \mathrm{~m})$ in the course of a day but excluding areas of obviously unsuitable topography. Foraging sites were the smaller individual portions of habitat covered by foraging birds moving on foot within a particular area. The survey in October 2007 was aimed at confirming that the same birds were wintering at the same site, and at briefly assessing the habitats and home range used. The surveys in November 2008 and January 2009 were aimed at supplementing behavioural ecology and conservation observations carried out in 2006. Since the VHF tags were not operational after 2006, birds were located by observing their direction of flight from their roots at dawn and by searching all suitable habitats within the area known to be used by ibises in the past. A preliminary socioeconomic and cultural survey was conducted during the 2008 and 2009 field trips (Kubsa 2009). Forty-three household representatives out of c.153 households in the IWR were randomly sampled and interviewed using a standard questionnaire. Additional information was gained by consulting local authority officers and community leaders.

\section{Results}

\section{Determination of the Ibis Wintering Range (IWR)}

The Northern Bald Ibises from Syria used the same wintering site in Ethiopia for five successive winters from 2006 to 2011. The timings and numbers of birds present are shown in Table 1 . After filtering, 442 satellite locations ( $41 \%$ of the total) were retained for analysis of home ranges. There was a high degree of overlap in the area used by the birds in each year (Figure I). The core area (50\% volume contour) used by the wintering ibises had a mean area $13.1 \mathrm{~km}^{2}$ $(\mathrm{CI}+/-3.5)$ whilst the wider range ( $95 \%$ volume contour) was $80.8 \mathrm{~km}^{2}(\mathrm{CI}+/-25.3)$ (Figure 2$)$. The annual areas used by the birds are shown in Table 1 . The area used by the ibises from all five years considered together was $10.6 \mathrm{~km}^{2}$ for the core and $100.5 \mathrm{~km}^{2}$ for the wider range. The core area was thus $10.6 \%$ of the wider range. The area shared by the annual $50 \%$ volume contours covered $81.1 \%$ of the $50 \%$ contour calculated from pooling data across all years. The equivalent figure for the $95 \%$ contour was $41.5 \%$. More stringent filtering for analysis of the foraging range ( $\mathrm{LC}_{2-3}$ only, nocturnal locations excluded) meant that of 116 acceptable locations only 17 came from the last three winters (and from only one bird), so the pattern is dominated by data from the first two years. The foraging range had a core area $(50 \%$ volume contour) of $12.1 \mathrm{~km}^{2}$ and a wider range (95\% contour) of $70.9 \mathrm{~km}^{2}$ (Figure 3 ). The satellite data also showed four excursions made outside the main wintering range for limited periods, the nearest being $7.5 \mathrm{~km}$ away from the usual roost and the furthest $27 \mathrm{~km}$ away. This latter excursion, at its furthest point, came within c. $6 \mathrm{~km}$ of the last known record of Northern Bald Ibis in Ethiopia from c.30 years ago, when six bald ibises were observed in January 1977 (Ash and Howell 1977). One of these four excursions likely entailed a change of roost for at least seven days in August 2007.

\section{Foraging habitats}

In November 2006, only two distinct foraging areas were used by all four ibises, located about $3 \mathrm{~km}$ apart from each other, with an estimated area of c.30.9 ha (area 1) and 247.6 ha (area 2). Birds were observed commuting between them several times a day. Ibises preferentially selected freshly cut hayfields at area 1 (chi-squared test $=195.33, \mathrm{df}=1, P<0.001$ ) and overgrazed 

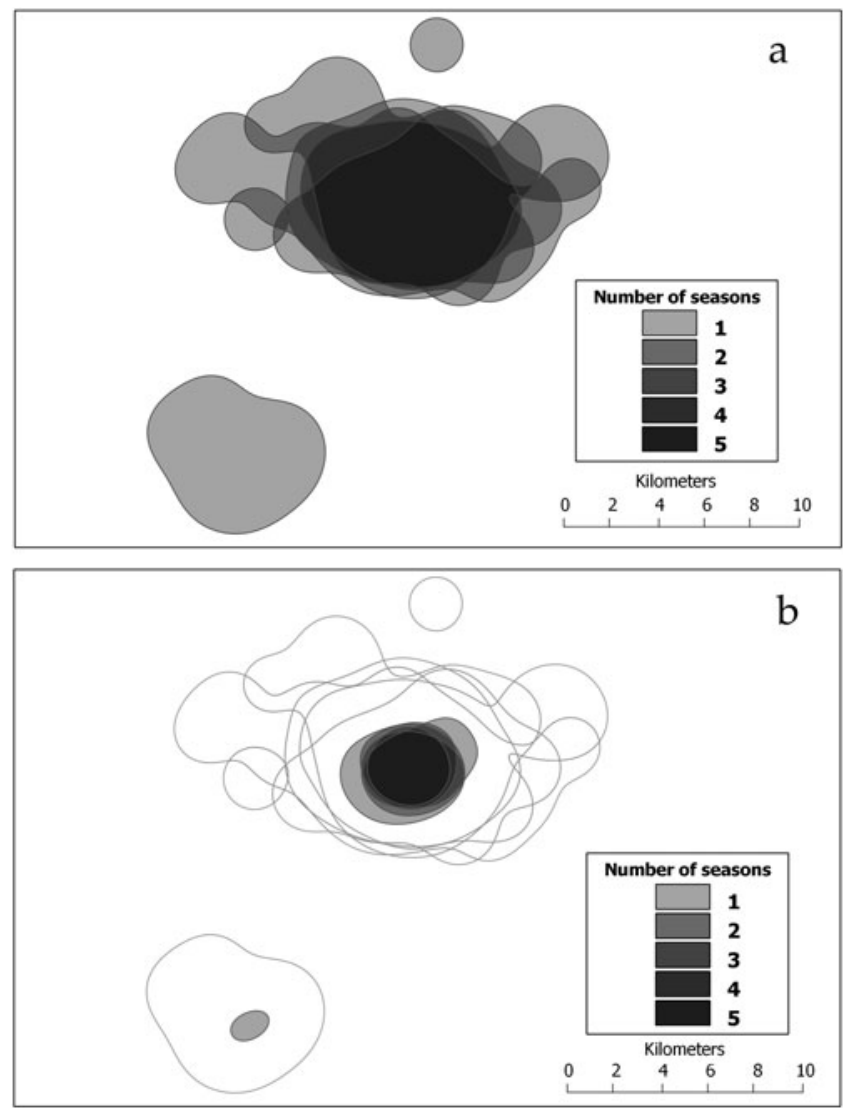

Figure 1. The degree of overlap of annual winter ranges across five consecutive winters in Ethiopia (2006/2007 to 2010/2011). Boundaries shown are volume contours from a kernel analysis of diurnal and nocturnal locations: a) overlap of the $95 \%$ volume contours with darker shaded areas being used in more years; b) overlap of the $50 \%$ volume contours with the $95 \%$ contours shown for reference.

pastures at foraging area 2 (chi-squared test $=262.17, \mathrm{df}=1, P<0.001$ ) (Figure 4 ). Cultivated and fully-grown hayfields in both areas were ignored. Freshly cut hayfields were used by birds for a few days after cutting until they had turned dry and yellowish. Birds used five different patches of pastures within area 2. In November 2008 and January 2009, ibises only used overgrazed pastures, even though $53 \%$ of the core IWR comprised cultivated fields and hayfields (both fully-grown and cut) (chi-squared test $=112.77, \mathrm{df}=1, P<0.001$ ) (Figure 4 ). Both sloping wet pastures in proximity to streams, and flat and dry higher pastures closer to villages were used. On the higher pastures they focused on drier patches probing cracks in the soil for larvae. Unlike in November 2006, ibises did not use freshly cut hayfields in November 2008, despite being apparently available.

\section{Behavioural observations}

The ibises moved as a flock on the wintering site. The daily pattern of usage of the two main foraging areas was rather stable during 2006. Few flights were observed and only during transfer from one foraging area to another. At times, foraging Northern Bald Ibises formed mixed flocks 


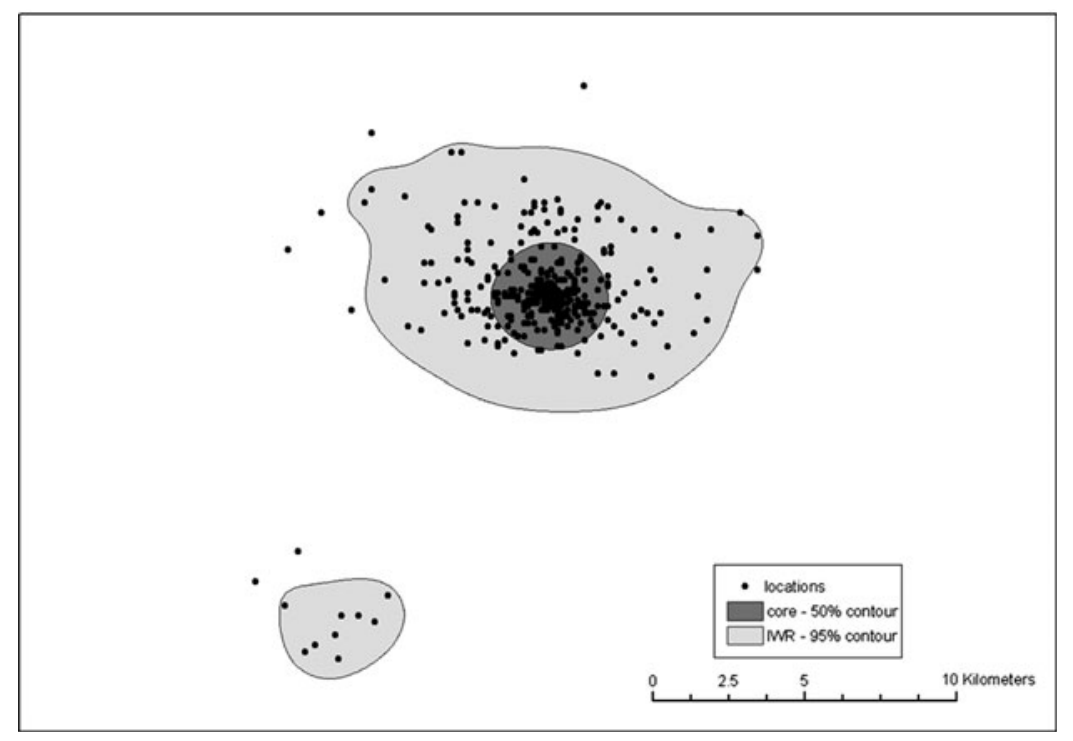

Figure 2. Winter range of N. Bald Ibises in Ethiopia estimated from diurnal and nocturnal satellite locations $(n=442)$ over five consecutive winters (2006/2007 to 2010/2011). Core and wider winter ranges are expressed by $50 \%$ and $95 \%$ volume contours of a kernel analysis (dark grey and light grey, respectively). The area of the $50 \%$ contour $=10.62 \mathrm{~km}^{2}$; area of the $95 \%$ contour $=$ $100.51 \mathrm{~km}^{2}$. Individual satellite locations of ibises are shown.

with Wattled Ibis Bostrychia carunculata, Cattle Egret Bubulcus ibis and Sacred Ibis Threskiornis aethiopicus especially when on hayfields close to streams. Foraging areas of Northern Bald Ibises and Wattled Ibises overlapped on hayfields, but the latter species also used fully-grown hayfields. Northern Bald Ibises were also seen resting together with Wattled and Sacred Ibises by ponds and streams. The all-day following of the Northern Bald Ibises showed that birds spent $55-85 \%$ of the day foraging and the rest on bathing, preening and resting. The roost site used by the Northern Bald Ibises was a patch of c.20m high Eucalyptus grandis trees (c.40-50 years old), in a small settlement on a low hill overlooking most of the IWR. The satellite data confirmed this as the habitual roost site. The trees were shared with roosting Pied Crows Corvus albus and 30-50 Wattled Ibises, Cattle Egrets and Sacred Ibises. The Northern Bald Ibises used the same individual tree during almost three winters (2006-2008) but were forced to move in January 2009 due to the felling of this tree by local people. Beside waterbirds and cranes, the area seems to be an important feeding/wintering site for birds of prey (vultures, eagles, harriers). Alert reaction behaviour and frequent looking at the sky were observed several times in relation to passage of large eagles (Aquila clanga, A. rapax and A. nipalensis). At times, proximity of a raptor would even prompt the sudden flushing of ibises. Northern Bald Ibises are fully dependent on human-modified habitats in the IWR. On most days they are in close proximity to people working in fields or herding livestock. Neither disturbance nor negative interaction was observed between the birds and the local community. We observed no significant difference in Northern Bald Ibis behaviour or their selection of feeding areas with people present or absent in November 2006 (working days versus Sundays). People do not show any interest towards birds foraging on the hayfields and on pastureland. Reportedly, local people, in line with their culture and traditional beliefs, do not usually hunt birds - though in some areas they may trap ground birds such as francolins. The most common observed interaction between birds and humans was a short flight (30-80 m) to avoid the close approach of people or herds of livestock. Most evasion by 


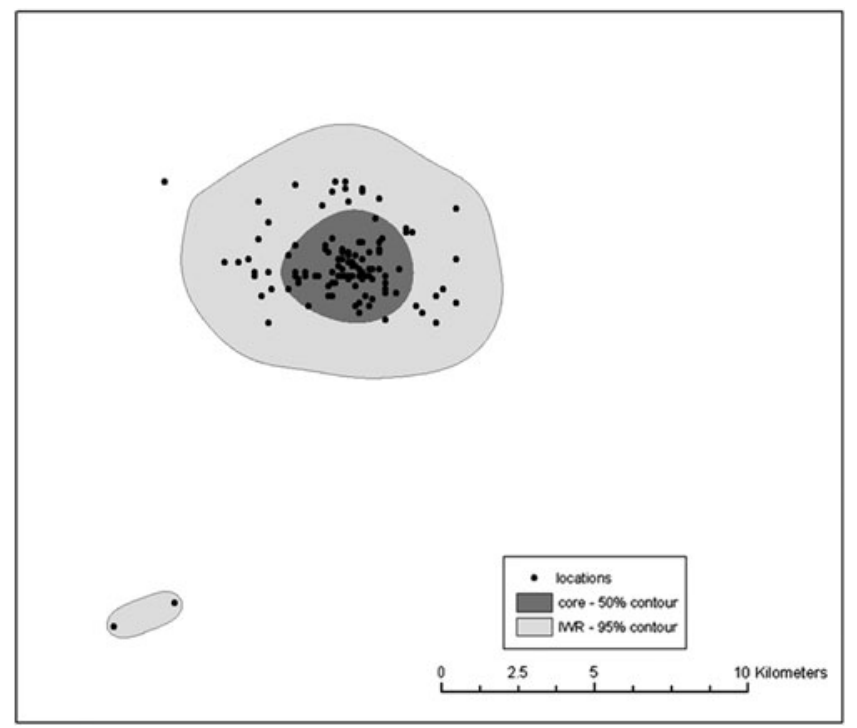

Figure 3. Winter foraging range of $\mathrm{N}$. Bald Ibises estimated from diurnal satellite locations $(n=116)$ over five consecutive winters (2006/2007 to 2010/2011). Core and wider winter ranges are expressed by $50 \%$ and $95 \%$ volume contours from a kernel analysis (dark grey and light grey, respectively). Area of $50 \%$ kernel $=12.10 \mathrm{~km}^{2}$. Area of $95 \%$ kernel $=70.89 \mathrm{~km}^{2}$. Individual satellite locations of ibises are shown.

the ibises was made on foot. As indicated above, the roost sites at times may become vulnerable to human disturbance.

\section{Socio-economic conditions}

The local community in the IWR belongs to the Oromo ethnic group, which is the largest in the country. In the IWR people typically subsist on rain-fed agriculture and livestock husbandry. There is neither electricity nor a road network in the area and illiteracy rates are high. Land is owned by the State and people have usage rights either as leaseholders or against payment of land revenue taxes. Most extended families, averaging 6-9 individuals, live in small settlements of straw-roofed huts. The population and household densities in the IWR were $0.55 /$ ha and $0.08 /$ ha respectively (2008-2009). Each household has its own cultivated fields and pastures adjacent to the settlement and owns on average 10-15 cattle, and sometimes also sheep, donkeys and horses. They use water from streams for drinking, cooking, bathing and washing. About $18 \%$ of the people living in the IWR and surrounding area are listed as food insecure and thus need some assistance in the form of food-for-work. Rain-fed crop cultivation is subject to nocturnal frost and annual variability in rainfall. The area can produce two harvests a year provided that rainfall is sufficient. However, in certain years the population is subjected to food shortages due to the failure of crops during one or both of the seasons. People interviewed in winter 2008/2009 described their main survival problems as rainfall variability, land shortage, decreasing soil fertility and erosion. Decreasing fertility and soil erosion have induced an increasing number of young people to emigrate to urban centres. Reportedly there had been some use of fertilisers, especially in the past, but this practice is decreasing due to rising costs. The local agricultural office promotes the use of organic fertiliser compost as opposed to inorganic synthetic fertilisers. It was reported that there has never been a significant use of pesticides within the district and no evidence to the contrary was noted during fieldwork. 


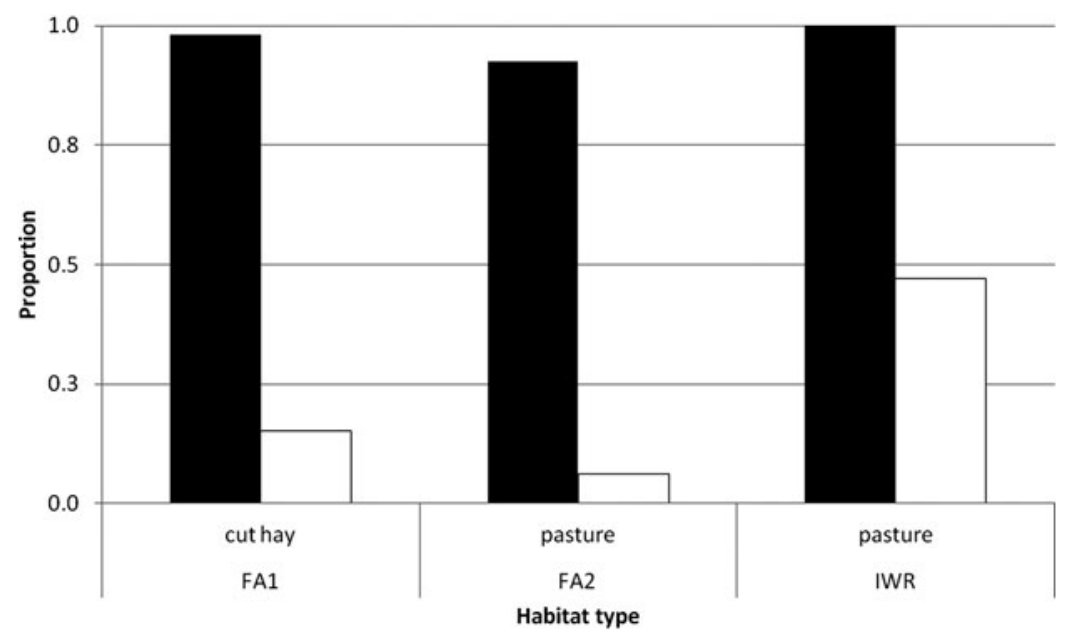

Figure 4. Three different comparisons are presented of time spent foraging by the four ibises in each habitat (usage/dark bars) versus the proportion of area available of each habitat type (availability/white bars) over three total areas considered: foraging area $I$ (FAI), foraging area 2 (FA2) and the IWR core range. Observations collected in FAI and FA2 were recorded during two full days in November 2006 while those collected within the core IWR were recorded during two full days in November 2008 and January 2009. In each area the remainder of the habitat consisted of cultivated ground or uncut hay (and cut hay in the case of IWR).

\section{Estimated threats}

We judge that the following issues have the potential to threaten the persistence of ibises at the wintering site:

Short to medium term

- external visitors and/or informed local authorities drawing the attention of local people toward the ibises and the markers they carry such as coloured rings and PTTs;

- rainfall shortages resulting in reduction in food availability for the local community;

\section{Medium to long term}

- conversion of hayfields and pastureland into cultivations;

- increased use of agricultural fertilisers or pesticides which are believed to be harmful to ibises.

\section{Discussion}

Satellite tracking of Northern Bald Ibises from the last known colony of the eastern population showed a high degree of winter site fidelity across five years (Berthold 2001), similar to that shown by Black Stork Ciconia nigra (Bobek et al. 2008) and cranes (Berthold 2001), and differing from the partial winter site fidelity observed in the White Stork C. ciconia (Van den Bossche 2002). Field observations, focused on the IWR core area, suggested almost complete overlap of the wintering range from year to year and satellite telemetry confirmed this across the five winters. Data clearly show that the area of overlap is in the centre of the ranges (both at 50 and $95 \%$ ) confirming IWR core area stability across years and ibis fidelity to it. Integration of satellite data and field observations suggested that within each winter period the home range tends to increase in size as ecological conditions dry out and food presumably becomes scarcer (Serra et al. 2006, 
Serra and Wondafrash 2009), as has been observed for wintering Black Storks (Chevallier et al. 2010a). The IWR location is consistent with past historical records of Northern Bald Ibises belonging to the eastern population (Welch and Welch 2005, Ash and Atkins 2009). The site is only 30 $\mathrm{km}$ from the last recorded observation of Northern Bald Ibises in Ethiopia (Ash and Howell 1977). The highland environment where the IWR is located, and its surroundings, are a mix of croplands, pasturelands and degraded stony savanna, an environment already identified as important for bird conservation (Aerts et al. 2008). Pastures may be more abundant at IWR than in other plateau areas where cultivated fields prevail and there are indications that the IWR is wetter than other areas in the Ethiopian highlands at an equivalent altitude (Kubsa 2009). The preference of Northern Bald Ibises for a relatively humid environment during winter in Ethiopia contrasts with their extremely arid breeding environment in Syria (Serra et al. 2009b) - although at wintering grounds they use both wet habitats (hayfields) and the dry pastures. The core breeding range for Northern Bald Ibis in Syria was estimated at $253 \mathrm{~km}^{2}$ (Serra et al. 2011), some 20 times larger than the estimated core wintering range in Ethiopia. The wider breeding range in Syria was 1,313 $\mathrm{km}^{2}$ (Serra et al. 2011), which is c.6o times larger than the wider wintering range in Ethiopia. Large differences in breeding and wintering home range size have also been observed in Black Storks (Chevallier et al. 2010a) though the difference was less pronounced in that species. For the ibises this difference is most easily explained by the substantial ecological contrast between the relatively humid Ethiopian highlands and the arid Syrian desert. The ratio between the core and the wider wintering range is similar in Northern Bald Ibis and Black Stork (Chevallier et al 2010a) but much smaller than in the ibis breeding grounds. Although these differences could be explained by the need for different food sources and energy requirements during winter versus breeding periods it could also be related to the serious ecological degradation of the Syrian steppe (Serra et al. 2009b), which far exceeds any degradation in the wintering site. The ibises proved to be quite consistent in their use of foraging areas and sites. Two feeding habitats were recorded to be used by birds during the field surveys: cut hayfields (as observed in November 2006) and pastures (as observed in November 2006, November 2008 and January 2009). Similarly two kinds of habitats are favoured by wild Northern Bald Ibis in Morocco (Bowden et al. 2008) and by handraised and semi-captive ibises in Austria and Italy (Zoufal et al. 2006). In Syria they complement the use of pastures as a source of food with the shores of artificial reservoirs, seasonally abundant in young frogs (Serra et al. 2008). However, during the two surveys undertaken in winter $2008 / 2009$ only pastures were observed to be used, despite the availability of freshly cut hayfields. It is not clear why the birds did not use cut hayfields that winter but it was possibly because of elevated prey levels in the pasture linked to the delayed termination of the long rainy season in that year. Unlike Wattled Ibis, Northern Bald Ibis avoided tall grass (Bowden et al. 2003, Kopij 2001) only using hayfields once they were cut. As on the breeding grounds (Serra et al. 2008) and unlike on migration (Serra 2010), ibises avoided cultivated fields for foraging at IWR, even abandoned fields, despite these being used by other birds such as Wattled Ibis and Common Crane Grus grus. Macro-invertebrates and micro-vertebrates observed in cut hayfields and pastures matched well with the diet of ibises at breeding grounds (Serra et al. 2006, 2008, Serra and Wondafrash 2009). By contrast, the diet of Black Storks at breeding and wintering grounds differed substantially (Chevallier et al. 2010a). Occurrence of water-bodies and safe sites along their shores is important for resting of ibis that typically takes place around mid-day, as was also observed at breeding grounds in Syria (Serra et al. 2008) and for White Storks (Van den Bossche 2002). The behaviour of the two ibis pairs at their wintering grounds was consistent across three winter seasons. They were very gregarious at IWR, as noted also at the breeding grounds (Serra et al. 2009a). Ibises started courtship displays at IWR in January 2009, some weeks before the spring migration, consistent with past observations that bald ibises would arrive in Birecik already paired (Pegoraro 1996) and with similar observations for cranes (McNulty 1966, Archibald and Meine 1996). Satellite tracking observations during return migrations in 2007 and 2008 suggested that one particular established pair migrated northward together, at least during the first part of the migration (unpubl. data). The ibises were also consistent in the use of a specific 
roost site, similar to what has been observed in the Syrian breeding grounds (Serra et al. 2009a) but differing from White and Black Storks (Van den Bossche 2002, Chevallier et al. 201ob). However, whereas they used a tree to roost in Ethiopia as they do along the migration route (Serra 2010) in the breeding area they depend on rocky cliffs (Serra et al. 2009a). On people approaching, recorded flight distances seemed quite short (around $30-80 \mathrm{~m}$ ) compared with that recorded on Syrian breeding grounds (100-150 m), suggesting less fear of humans at IWR. This is consistent with the more severe human disturbance observed in Syria than in Ethiopia (Serra et al. 2009a), despite a lower human density at the former (Chevallier et al. 2010a): this is due to the greater accessibility of the breeding environment to vehicles and also to the fact that hunting is deeply rooted in the Arab desert culture (and enforcement of regulations is insufficient). Observation of intense gazing at the sky and alarming behaviour during the passage of large eagles (Aquila spp.) over the wintering site, suggested that bald ibises might be preyed upon by these large raptors (Loretto et al. 2009). Overall, no evident short-term threat was recognised during the winter surveys, except that attracting too much interest on the part of the local community towards the ibises might confer unwelcome attention on them. The chances are that even in these very favourable conditions, it would be extremely difficult to eliminate the potential risks to which 3-4 birds might become suddenly exposed, without establishing an intensive awareness and protection programme. Therefore, subject to periodic reassessment, the most cost-effective conservation approach to maintain the current situation where the birds remain undisturbed seems to consist of not publicising the occurrence of these birds or paying unnecessary visits to the site. A key threat to the birds in the medium and long term comes from the precariousness of the local subsistence economy that seems to be becoming increasingly unsustainable as ecological degradation of the agro-ecosystem proceeds. The typical annual variation in rainfall on the Ethiopian highlands has negatively combined in recent decades with increasing soil infertility and erosion, and with "land shortage" as described by Kubsa (2009) relative to IWR. Traditional agriculture has been carried out for millennia on the Ethiopian highlands (Fenta 2000), but population density in Ethiopia has reached unprecedented levels during recent decades (CSA 2008) and the Ethiopian highlands have become among the most densely populated agricultural areas in Africa (WWF 2011). Unlike other parts of Ethiopia, IWR does not seem to present a short-term threat from agricultural intensification through irrigation and the use of fertilisers and pesticides, which are likely to be detrimental to the ibis foraging habitat (Hirsch 1977, Akcakaya 1990), but this specific issue needs on-going monitoring.

We conclude that the steady decline of the colony of Northern Bald Ibis breeding in Syria is most likely not caused by impacts on the wintering grounds in Ethiopia. As a consequence, urgent attention needs to be focused on threats along the migratory route and at its key staging sites.

\section{Recommendations}

\section{Short term}

- Undertake low profile visits to monitor the birds and their habitats every 2-3 years

- ensure contact with local authorities to ensure their cooperation in not publicising the site

- dissuade birdwatchers from visiting the area (geographic coordinates and the name of the site should not be publicised)

\section{Medium term}

- review any land-use changes in the area bi-annually

- search for possible additional bald ibises wintering on the central Ethiopian plateau

- should the Syrian colony start to recover, plan for ecologically sustainable poverty reduction schemes in the area and raise levels of ecological awareness (Dejene et al. 2004). 


\section{Acknowledgements}

We are indebted to the District of Agriculture and Rural Development Office (DARDO), especially to Mr Getiye Girma and Mr Gutta Haleko, and to Mr Getu Robi and Mr Tashome Yifru from Abicu fi Nya'a District Agricultural Office. In particular, we warmly thank Mr Solomon Feyisaa, the Chairperson of Doyo-Dawee Peasant Association, and all the local community interviewed. Field surveys were carried out in cooperation with, and full involvement of, the competent local authority, the Agricultural District of Mendida. The surveys were organised by the Ethiopian Wildlife Natural History Society (EWNHS), with financial support by National Geographic Society, the Italian Development Cooperation Program (DGCS), RSPB, Chester Zoo and the African Bird Club/Wildwings Annual Conservation Award.

\section{References}

Ackerman, B. B., Leban, F. A., Garton, E. O. and Samuel, M. D. (1989) User's manual for program home range. 2nd edition. University of Idaho, Moscow, ID: Wildlife Range Experimental Station.

Aerts, R., Lerouge, F., November, E., Lens, L., Hermy, M. and Muys, B. (2008) Land rehabilitation and the conservation of birds in a degraded Afromontane landscape in northern Ethiopia. Biodivers. Conserv.17: 53-69.

Akcakaya, H. R. (1990) Bald Ibis Geronticus eremita population in Turkey: an evaluation of the captive breeding project for reintroduction. Biol. Conserv. 51: 225-237.

Archibald, G. W. and Meine, C. (1996) Family Gruidae (Cranes). Pp. 6o-89 in J. Del Hoyo, A. Elliott and J. Sargatal, eds. Handbook of the birds of the world. Vol. 3 Hoatzin to auks. Barcelona, Spain: Lynx Edicions.

Ash, J. S. and Howell, T. R. (1977) The Bald Ibis or Waldrapp Geronticus eremita in Ethiopia. Bull. Br. Orn. Club 97: 104.

Ash, J. S. and Atkins, J. (2009) Birds of Ethiopia and Eritrea: an atlas of distribution. London, UK: A\&C Black Ltd.

Bairlein, F. (1981) Okosystemanalyse de Rastplatze von Zugvogeln: Beschreibung und Deutung der Verteilungsmuster von ziehenden Kleinvliegeln in verschiedenen Biotopen der Stationen des "Mettnau-ReitIllmitz" Programmes. Okol. Vogel 3: 7-137.

Bairlein, F. (2003) The study of bird migrations some future perspectives. Bird Study 50: 243-253.

Berthold, P. (2001). Bird migration: a general survey. Oxford, UK: Oxford University Press.
Berthold, P. and Terrill, S. B. (1991) Recent advances in studies of bird migration. Ann. Ecol. Syst. 22: 357-378.

BirdLife International (2004) Geronticus eremita. In IUCN 2006. 2006 IUCN Red List of Threatened Species.www.iucnredlist. org, downloaded on o9 June 2012.

Bobek, M., Hampl, R., Peske, L., Pojer, F., Simek, J. and Bures, S. (2008) African Odyssey project - satellite tracking of black storks Ciconia nigra breeding at a migratory divide. J. Avian Biol. 39: 500-506.

Bowden, C. G. R. and Smith, K. W. (1997) Conservation of the Bald Ibis in the Souss-Massa National Park. Sandy, UK: RSPB internal report.

Bowden, C. G. R., Aghnaj, A., Smith, K. W. and Ribi, M. (2003)The status and recent breeding performance of the last known wild population of northern bald ibis Geronticus eremita, on the Atlantic coast of Morocco. Ibis 145: 419-431.

Bowden, C. G. R., Smith, K. W., El Bekkay, M., Oubrou, W., Aghnaj, A. and JimenezArmesto, M. (2008) Contribution of research to conservation action for the Northern Bald Ibis Geronticus eremita in Morocco. Bird Conserv. Internatn.18: 74-90

Broomhall, L. S., Mills, M. G. L. and Du Toit, J. T. (2003) Home range and habitat use by cheetahs (Acinonyx jubatus) in the Kruger Park. J. Zool. 261: 119-128.

Central Statistical Authority (CSA) (2008) Summary and statistical report of the 2007 population and housing census - population size by age and sex. Federal Democratic 
Republic of Ethiopia: Population Census Commission.

Chevallier, D., Le Maho, Y., Baillon, F., Duponnois, R., Dieulin, C., Brossault, P., De Franclieu, P., Lorge, P., Aurouet, A. and Massemin, S. (2010a) Human activity and the drying up of rivers determine abundance and spatial distribution of Black Storks Ciconia nigra on their wintering grounds. Bird Study 57: 369-380

Chevallier, D., Duponnois, R., Baillon, F., Brossault, P., Grégoire, J.-M., Eva, H., Le Maho, Y. and Massemin, S. (2010b)The importance of roosts for Black Storks Ciconia nigra wintering in West Africa. Ardea 98: 91-96.

Dejene, A., Zeleke, G., Abate, S. and Lule, M. (2004) Towards sustainable agriculture and rural development in the Ethiopian highlands. Proceedings of the Technical Workshop on Improving the Natural Resources Base and Rural Well-being, Bahir Dar, Ethiopia, 25- 27 November 2003. Rome, Italy. (FAO Environment and Natural Resources Working Paper No. 17).

Dellelegn, Y. (2011) Northern Bald Ibis Survey Report - Ethiopia. Addis Ababa: Ethiopian Wildlife Society internal report.

FAOSTAT http://faostat.fao.org (Last accessed: 3 February 2012).

Fenta, T. (2000) Biodiversity conservation and utilization on the basis of farmers traditional knowledge: Ethiopian experience. UNCTAD Expert Meeting on Systems and National Experiences for Protecting Traditional Knowledge, Innovations and Practices, Geneva, 30 October-1 November 2000.

Gauthier, G., Milot, E. and Weimerskirch, H. (2010) Small-scale dispersal and survival in a long-lived seabird, the wandering albatross. J. Anim. Ecol.79: 879-882.

Hirsch, U. (1977) Artificial nest ledges for Northern Bald Ibises. Pp. 61-69 in S. A. Temple, ed. Endangered birds: management techniques for preserving threatened species: Madison, Wisconsin: University of Wisconsin Press.

Hobbs, R. C., Laidre, K. L., Vos, D. J., Mahoney, B. A. and Eagleton, M. (2005) Movements and area use of belugas, Delphinapterus leucas, in a subarctic Alaskan estuary. Arctic 58: 1479-1487.
Hooge, P. N., Eichenlaub, W. M. and Solomon, E. K. (2004) Using GIS to analyze animal movements in the marine environment. Fairbanks, Alaska: U.S. Geological Survey, Alaska Biological Science Center. Unpublished report. Available at: http:// www.absc.usgs.gov/glba/gistools, downloaded on 26 April 2010.

Kanyamibwa, S., Schierer, A., Pradel, R. and Lebreton, J.-D. (1990) Changes in adult annual survival rates in a western European population of the White Stork Ciconia ciconia. Ibis 132: 27-35.

Kopij, G. (2001) Feeding ecology of the Southern Bald Ibis, Geronticus calvus, in the Free State, South Africa. Ostrich 72: 193-198.

Kubsa, A. (2009) Ethiopian Wildlife and Natural History Society / IUCN preliminary socio-economic and cultural survey at $N$. Bald Ibis wintering area in northern Shawa, Ethiopia. Final report. Addis Ababa: IUCN/DGCS trust fund pilot project.

Lindsell, J., Serra, G., Abdallah, M. S., al Qaim, G. and Peske, L. (2009) Satellite tracking reveals the migration route and wintering area of the Middle Eastern population of Northern Bald Ibis. Oryx 196: 329-335.

Lindsell, J. A., Shehab, A. and Anderson, G. (2011) Patchiness in prey levels increases vulnerability of critically endangered Northern Bald Ibises Geronticus eremita on their Syrian breeding grounds. Bird Conserv. Internatn. 21: 274-283.

Loretto, M.-C., Schloegl, C. and Bugnyar, T. (2009) Northern bald ibises follow others' gaze into distant space but not behind barriers. Biol. Lett. 61: 14-17.

McNulty, F. (1966) The Whooping Crane. New York, USA: E. P. Dutton.

Menu, S., Gauthier, G. and Reed, A. (2005) Survival of young Greater Snow Geese (Chen caerulescens atlantica) during fall migration. Auk 122: 479-496.

Meyburg, B.-U. And Meyburg, C. (2007) Quinze années de suivi de rapaces par satellite. Alauda 75: 265-286.

Newton, I. (2004) Population limitation in migrants. Ibis 146: 197-226.

Pegoraro, K. (1996) Der Waldrapp: vom Ibis, den man für einen Rabenhielt. Wiesbaden: Aula Verlag. 
Pistorius, P. A., Follestad, A. and Taylor, F. E. (2006) Declining winter survival and fitness implications associated with latitudinal distribution in Norwegian Greylag Geese Anser anser. Ibis 148: 114-125.

Rodgers, A. R. and Carr, A. P. (1998) HRE: The Home Range Extension for Arcview. Thunder Bay, Ontario, ON: Ministry of Natural Resources, Centre for Northern Forest Ecosystem Research.

Saino, N., Szep, T., Ambrosini, R., Romano, M. and Pape Moller, A. (2004) Ecological conditions during winter affect sexual selection and breeding in a migratory bird. Proc. R. Soc. Lond. B 271: 681-686.

Sanderson, F. J., Donald, P. F., Pain, D. J., Burfield, I. J. and van Bommel, F. P. J. (2006) Long-term population declines in Afro-Palearctic migrant birds. Biol. Conserv. 131: 93-105.

Schultz, D. F., Cooper, J. A. and Zicus, M. C. (1988) Fall flock behavior and harvest of Canada geese. J. Wildl. Manage. 52: 679-688.

Seaman, D. E. and Powell, R. A. (1996) An evaluation of the accuracy of kernel density estimators for home range analysis. Ecology 77: 2075-2085.

Serra, G. (2010) Report on Northern Bald Ibis expedition in Saudi Arabia, March 2010. Unpublished report, grant \#8479-08 of the National Geographic Society's Committee for Research and Exploration.

Serra, G. and Wondafrash, M. (2009) Ecoethological and conservation survey of $\mathrm{N}$. Bald Ibises wintering in the northern Shawa (Ethiopia) during 2008-09. Unpublished report, project \# 76812-040, IUCN West Asia/DGCS Trust Fund.

Serra, G., Abdallah, M., Abdallah, A., Al Qaim, G., Fayed, T., Assaed, A. and Williamson, D. (2004) Discovery of a relict breeding colony of Northern Bald Ibis Geronticus eremita in Syria: still in time to save the eastern population? Oryx 38: 1-7.

Serra, G., Peske, L. and Wondafrash, M. (2006) First survey of eastern N. Bald Ibises Geronticus Eremita wintering on the Ethiopian highlands. Unpublished report, grant \#7993-06 of the National Geographic Society's Committee for Research and Exploration.

Serra, G., Abdallah, M. S. and Al Qaim, G. (2008) Feeding ecology and behaviour of the last known surviving oriental Northern Bald Ibises Geronticus eremita (Linnaeus 1758) at their breeding quarters in Syria. Zool. Middle East 43: 55-68.

Serra, G., Peske, L., Abdallah, M. S., Al Qaim, G. and Kanani, A. (2009a) Breeding ecology of the last oriental N. Bald Ibises in the Syria desert. J. Ornithol. 150: $769-782$.

Serra, G., Nahaz, M. M., Idan, M., Peske, L., Savioli, A., Bruschini, C. and Alomari, K. (2009b) Assessment and characterization of the Ibis Protected Area in the Palmyra Desert - a proposed 5-year management and development framework. Damascus, Syria: IUCN/DGCS (Italian Development Cooperation Program).

Serra, G., Bruschini, C., Lindsell, J., Peske, L. and Kanani, A. (2011) Breeding range of the last eastern colony of critically endangered N. Bald Ibises Geronticus eremita in the Syrian steppe: a threatened area. Bird Conserv. Internatn. 21: 284-295.

Serra, G., Lindsell, J. A., Peske, L., Fritz, J., Bowden, C. G. R., Bruschini, C., Welch, G., Tavares, J. and Wondafrash, M. (in press) Accounting for very low survival of a Critically Endangered bird on a major migratory flyway. Oryx.

Soderstrom, B., Kiema, S. And Reid, R. S. (2003) Intensified agricultural land-use and bird conservation in Burkina Faso. Agr. Ecosyst.Environ. 99: 113-124.

Thaxter, C. B., Joys, A. C., Gregory, R. D., Baillie, S. R. And Noble, D. G. (2010) Hypotheses to explain patterns of population change among breeding birdspecies in England. Biol. Conserv. 143: 2006-2019.

Tilman, D., Cassman, K. G., Matson, P. A., Naylor, R. and Polasky, S. (2002) Agricultural sustainability and intensive production practices. Nature 418: 671-677.

Van den Bossche, W. (2002) Eastern European White Stork populations: migration studies and elaboration of conservation measures. Final Report of the F+E-Project.

Vashon, J. H., Meehan, A. L., Jakubas, W. J., Organ, J. F., Vashon, A. D., Laughlin, Mc, C. R., Matula, G. J., Jr. and Crowley, S. M. (2008) Spatial ecology of a Canada Lynx population in northern Maine. J. Wildlife Manage. 72: 1479-1487. 
Webster, M. S., Marra, P. P., Haig, S. M., Bensch, S. and Holmes, R. T. (2002) Links between worlds: unraveling migratory connectivity. Trends Ecol.Evol.17: 76-83.

Welch, G. and Welch, H. (2005) Movements of the eastern population of Northern Bald Ibis Geronticus eremita in the Middle East. IAGNBI newsletter 3: 66-72.

Wernham, C., Toms, M. P., Marchant, J. H., Clark, J. A., Siriwardena, G. M. and Baillie, S. R. (2002) The migration atlas: movements of the birds of Britain and Ireland. London, UK: T. and A.D. Poyser.

Wiktander, U., Olsson, O. and Nilsson, G. (2001) Seasonal variation in home-range size, and habitat area requirement of the lesser spotted woodpecker (Dendrocopos minor) in southern Sweden. Biol. Conserv. 100: $387-395$.

Worton, B. J. (1989) Kernel methods for estimating the utilization distribution in home-range studies. Ecology 70: 164-168.
Worton, B. J. (1995) Using Monte Carlo simulation to evaluate kernel based home range estimators. J. Wildl. Manage. 59: 794-80o.

WWF (2011) Ecoregions: Ethiopian highlands. http://wwf.panda.org/about_our_ earth/ecoregions/ethiopian_highlands.cfm (Last accessed: 15 May 2011).

Zoufal, K., Fritz, J., Bichler, M., Kirbauer, M., Markut, T., Meran, I., Wolf, A. and Kotrschal, K. (2006) Feeding ecology of the Northern Bald Ibis in different habitat types: an experimental field study with hand-raised individuals. Vejer, Spain: Proceedings of the International Advisory Group for the Northern Bald Ibis (IAGNBI). Pp $77-83$.

Zwarts, L., Bijlsma, R. G., van der Kamp, J. and Wymenga, E. (2009) Living on the edge: wetlands and birds in a changing Sahel. Zeist, The Netherlands: KNNV Publishing.

\section{G. SERRA*}

Clo Secretariat of the Pacific Regional Environment Programme, P.O. Box 240, Apia, Samoa.

\section{BRUSCHINI}

Dipartimento di Biologia, Università degli Studi di Firenze, via Romana 17,50125, Florence, Italy.

\section{PESKE}

Slezska 43, Prague 3, 13000, Czech Republic.

\section{A. KUBSA, M. WONDAFRASH}

Ethiopian Wildife and Natural History Society, P.O. Box 13303, Addis Ababa, Ethiopia.

\section{J. A. LINDSELL}

The Royal Society for the Protection of Birds, The Lodge, Sandy, Beds SG19 2DL, UK.

*Author for correspondence; email: gianlucas@sprep.org

Received 31 March 2013; revision accepted 17 July 2013; Published online 29 October 2013 